\title{
The mystique surrounding the central bank's balance sheet, applied to the European crisis
}

\author{
By Ricardo Reis*
}

The New Oxford American Dictionary defines mystique as "a fascinating aura of mystery, awe, and power surrounding someone or something". This characterization applies to the balance sheet of a central bank. It has fascinating liabilities, dominated by currency and bank reserves, which are legal tender that cannot be converted into anything else than what they already are. There is an aura of mystery around the central bank's accounts, which follow peculiar accounting principles like the Federal Reserve valuing its securities using face value rather than market value, or the large TARGET2 claims from some members of the Eurosystem on the others. The central bank is perceived with awe to have immense power in part because it can fund unlimited purchases of any asset, and it is usually successful at fixing one key price in an economy, whether it is the short-term rate or the exchange rate. Some even argue that a country with its own central bank can never go through a sovereign default, because it can always pay debts with newly-created reserves.

This paper works through the resource constraint of a central bank to remove some of this mystique. From an accounting perspective, it is difficult to keep track of the value of the assets and liabilities in a central bank's balance sheet. Not only are these assets and liabilities peculiar, but there are also no accounting standards that naturally apply to a central bank, which is neither a private corporation nor a conventional government agency. Yet, from an economic perspective, a central bank is an

\footnotetext{
* Columbia University, 420 West 118th Street, New York, NY 10027, Email: rreis@columbia.edu. I am grateful to the euro-nomics group for motivating this work, to Robert Hall for many insightful discussions, to Anil Kashyap for comments, and to a grant from the Institute for New Economic Thinking for funding.
}

agent with limited resources. Keeping track of the sources and uses of these resources reveals what the central bank can and cannot achieve.

The analysis applies to a generic central bank in an advanced economy, but for concreteness I will refer to it as the Eurosystem or ECB, and to the euro as the currency. Each section poses a question that is inspired by discussions of the ECB's role during the recent crisis. The main conclusion is that the central bank's main power is to raise its inflation target, but otherwise its balance sheet gives it little leeway to pursue other goals.

\section{Does a central bank have unlimited resources?}

A central bank has two different types of liabilities. One of them is special because it gives its holders a return below the market return, which I simplify to zero. There is demand for these assets because they provide some service, perhaps as a means of payment or perhaps as safe collateral. I use $h_{t}$ to denote their amount in euros. Their main component are banknotes in circulation. The other type of liability is just like any other financial asset and must therefore pay the safe market return. One example are the trillions of dollars of excess overnight reserves in the United States during the recent financial crisis. I denote their total amount by $v_{t}$, and the safe promised return they pay between $t$ and $t+1$ is $i_{t}$.

On the side of assets, most of the times central banks hold a limited set of treasury securities plus some foreign exchange reserves but, during a crisis, the size and scope of their assets significantly enlarges (Reis, 2009). I assume there are $J$ assets, each earning a potentially stochastic return $i_{t+1}^{j}$, and the central bank holds $a_{t}^{j}$ euros of 
each asset for a total amount $a_{t}=\sum_{j} a_{t}^{j}$.

Finally, the central bank pays a dividend to the treasury, $d_{t}$ in real terms. Hall and Reis (2012) discuss how different rules on setting dividends affect the solvency of the central bank and its independence from fiscal authorities. Here, I study how large $d_{t}$ can be to measure of the real resources generated by the central bank.

Combining all of these elements, the resource constraint of the central bank is:

$$
\begin{aligned}
& h_{t+1}+v_{t+1}=h_{t}+\left(1+i_{t}\right) v_{t}+ \\
& \quad a_{t+1}-\sum_{j=1}^{J}\left(1+i_{t+1}^{j}\right) a_{t}^{j}+p_{t+1} d_{t+1}
\end{aligned}
$$

at all dates, where $p_{t}$ is the price level. This law of motion for the total liabilities of the central bank shows that it must raise new funds, $h_{t+1}+v_{t+1}$, in order to: (i) pay for the outstanding special liabilities and interestbearing liabilities, $h_{t}+\left(1+i_{t}\right) v_{t}$, (ii) expand the balance sheet by buying new assets, $a_{t+1}$ in excess of the gross return on last period's assets $\sum_{j=1}^{J}\left(1+i_{t+1}^{j}\right) a_{t}^{j}$, and (iii) pay dividends of $p_{t+1} d_{t+1}$ euros.

What makes the $v_{t+1}$ liabilities safe is the central bank standing ready to exchange them on par for currency, which is part of $h_{t+1}$. This commitment also implies that the central bank does not independently choose the composition of its liabilities. If agents suddenly desire to exchange $v_{t+1}$ for $h_{t+1}$ or vice-versa, the central bank must accommodate this desire. There is a common misconception that the central bank can just print banknotes, raise $h_{t+1}$, and therefore fund an unlimited amount of resources paid out, $d_{t+1}$. This is not correct, because $h_{t+1}$ is not an exogenous variable. Rather, it is endogenously determined because of the commitment to keep $h_{t+1}$ on par with $v_{t+1}$.

The central bank affects $h_{t+1}$ but through interest rates and inflation. To see this, let $s_{t+1}=\left(h_{t+1}-h_{t}\right) / p_{t+1}$ stand for the real seignorage resources. Their value is the sum of the payoffs in different states of the world weighted by the real stochastic discount factor (SDF), $m_{t, t+1}$. To value payoffs at further dates, the SDF is $m_{t, T}=$ $\prod_{\tau=t+1}^{T} m_{\tau-1, \tau}$. The value of asset holdings then satisfies the condition:

$$
a_{t}=\mathbb{E}_{t}\left[\frac{m_{t, t+1} p_{t}}{p_{t+1}} \sum_{j=1}^{J}\left(1+i_{t+1}^{j}\right) a_{t}^{j}\right]
$$

where $\mathbb{E}$ is the expectations operator. In turn, the safe rate of return is the inverse of the value of an asset that pays off $€ 1$ for sure next period. Multiplying by the SDF and taking expectations on both sides of equation (1) gives the expected value of the resources generated by the central bank, where a hat denotes the real value of asset holdings:

$$
\begin{aligned}
& \mathbb{E}_{t}\left(m_{t, t+1} d_{t+1}\right)=\mathbb{E}_{t}\left(m_{t, t+1} s_{t+1}\right) \\
- & \mathbb{E}_{t}\left[m_{t, t+1}\left(\hat{a}_{t+1}-\hat{v}_{t+1}\right)\right]+\left(\hat{a}_{t}-\hat{v}_{t}\right) .
\end{aligned}
$$

This expression shows that the central bank has two sources of resources. The first source is expected seignorage generated by expanding the special liabilities of the central bank. Because the central bank can use these funds to invest in assets that earn market interest rates, it can create resources. From another perspective, these liabilities are special because they provide a service to economy agents, for which the central bank will collect some revenue.

There is a strict limit to this revenue. The central bank is committed to satisfy the demand for these special liabilities by exchanging them on par with its other liabilities. There are many models of this demand, starting with the classic model of Cagan (1956), and they all predict that velocity, the ratio of nominal expenditure to $h_{t}$, increases with the nominal interest rate. Letting $L(i)$ be the inverse of velocity, so $L^{\prime}() \leq$.0 , seignorage revenue as a ratio of expenditures is:

$$
L\left(i_{t+1}\right)-\frac{L\left(i_{t}\right)}{1+g_{t+1}},
$$

where $g_{t+1}$ is the growth rate of nominal expenditures.

There are two relevant properties of the function defined by this expression. First, 
the central bank can only increase it by generating higher nominal interest rates or higher nominal expenditure growth. This is only possible in a sustained way with higher inflation. Second, countless theoretical and empirical studies have found that there is a maximum to this inflation tax. Over the past decade, the average value of seignorage in the Euro-area has been $0.6 \%$ of GDP and it has never been above $0.9 \%$. Hilscher, Raviv and Reis (2013) estimate that the theoretical maximum is a small multiple of the average. The central bank's ability to generate seignorage revenues is limited and depends on tolerating higher inflation.

The second and third terms on the righthand side of equation (3) show that the central bank can also fund an increase in dividends by either selling assets or increasing its market liabilities. When a central bank performs an open market operation, this does not happen. It purchases assets from financial institutions by crediting their accounts at the central bank, so the procedure by which the central bank raises $a_{t+1}$ involves an automatic expansion in $v_{t+1}$. The value of $a_{t+1}-v_{t+1}$ is unchanged.

\section{Can the central bank be a source of significant revenues?}

Besides open-market operations, there is a long list of unconventional policies that central banks can pursue with their balance sheet. In terms of the resource constraint, there are many possible combinations of changes in asset holdings and liabilities that can temporarily raise dividends. It is more useful to focus on the total amount of resources the central bank can generate over its potentially infinite horizon.

Let $D_{t}$ be the expected present value of future dividends, defined by the recursion:

$$
D_{t}=\mathbb{E}_{t}\left[m_{t, t+1}\left(d_{t+1}+D_{t+1}\right)\right]
$$

and likewise for the expected present value of future seignorage $S_{t}$. Then, iterating the resource constraint in equation (3) forward to infinity gives the inequality:

$$
D_{t} \leq S_{t}+\hat{a}_{t}-\hat{v}_{t} .
$$

The inequality comes from realizing that $\lim _{T \rightarrow \infty} \mathbb{E}_{t}\left[m_{t, T}\left(\hat{a}_{T}-\hat{v}_{T}\right)\right] \geq 0$. The $v_{t}$ are central bank liabilities that private agents do not value beyond their return, so the central bank should not be able to run a Ponzi scheme with them.

This expression gives an upper bound on the resources the central bank can generate. The previous section discussed why seignorage revenues are bounded above. In turn, $a_{t}-v_{t}$ is an initial condition inherited by the central bank. Hilscher, Raviv and Reis (2013) empirically estimate this upper bound finding modest values. Hall and Reis (2012) show that if the central bank follows a real mark-to-market rule in calculating its net income and pays it all every period, then $a_{t}-v_{t}$ is constant over time, so the central bank budget constraint reduces to paying all of its seignorage as dividends.

\section{Can the central bank redistribute resources across regions?}

The Eurosystem pays dividends to many fiscal authorities. Equation (6) constrains the total amount of dividends it can pay, but not how they are distributed. The central bank could, in principle, send the whole of $D_{t}$ to just one of its member states. For a small European country, this could be well above $100 \%$ of its GDP.

However, almost all central banks have very strict rules forbidding these redistributions. In the United States, the Federal Reserve can only distribute dividends to the federal treasury, not to the state treasuries. In the Euro-area, the Eurosystem's dividends are distributed according to a strict key that equally weights the country's share in the total population and GDP of the European Union. The central bank has no discretion on how to distribute $D_{t}$.

The central bank could redistribute resources in an alternative way. While keeping $a_{t}-v_{t}$ unchanged, the central bank could hold more assets issued by one region and fewer assets from the remaining regions. Likewise, it could borrow less from one region and borrow more from others. Either of these actions would effectively lend on net to that region, while borrowing 
from the rest. Because the no-Ponzi scheme condition applies only to the central bank's total borrowing, in principle it could do this forever.

Again though, this economically feasible operation is ruled out by the statutes of most central banks. The Federal Reserve can only hold securities that are not federally-issued or federally-backed in temporary and exceptional circumstances. In the Eurosystem, when one financial institution moves its deposits from the central bank of one country to another, the liabilities to the private sector of the first central bank fall, while the liabilities of the second central bank rise. But, via the TARGET2 system, this transaction is recorded in the Eurosystem as a liability of the first country to the second. The total liabilities $v_{t}$ of each country are unchanged.

Moreover, in the refinancing operations that account for most of the changes in its assets, the ECB uses repo operations accepting any collateral from its acceptable list. Therefore, it effectively does not control the composition of $a_{t}$. If many borrowers appear at the ECB's auctions offering as collateral securities from only one country, the composition of the ECB's assets will shift towards that country, and the ECB can do nothing to stop it.

If the sovereign states that own the central bank wish to use its balance sheet to redistribute resources, they can. But, in its normal operations, the members of the Eurosystem by themselves cannot control the composition of $v_{t}$ or $a_{t}$, so they cannot redistribute resources across regions.

\section{Can the central bank peg sovereign spreads?}

During the financial crisis, the ECB went beyond its normal operations, buying sovereign bonds issued by some of the countries in the euro-area. In principle, a central bank could peg the sovereign spread between two regions that share the same currency. Imagine the central bank announces the following standing facility: it will stand ready to buy and sell a periphery sovereign bond in exchange for a center sovereign bond at a target spread. The central bank can back this facility by raising or lowering its liabilities as is necessary. To ensure no arbitrage, the market prices must move to this target spread.

This comes with implications for the central bank's portfolio. If the central bank pegs the yield in the periphery too low, then all private investors will appear at the central bank's facility program selling their bonds by more than what they think the bonds are worth. The central bank's holdings would end up absorbing the whole supply of the periphery bond.

Alternatively, assume for simplicity that sovereign bonds have a maturity of one period, and that the periphery bond can either pay $€ 1$ next period, or instead $c \leq 1$ to its private holders. If the central bank can lower the risk-neutral probability of the latter event, if could lower the yield spread. The most effective way to do so would be to stimulate expenditures in this default state, so that by diminishing marginal utility, euros in the default state become less valuable. This stimulus would likely come with higher inflation.

The other way to target a yield is to target a payment in the default state that is close to 1 . To evaluate this possibility, the next section introduces a simple model of sovereign default.

\section{Can the central bank prevent sovereign defaults?}

The model rests on two pillars. The first is the budget constraint of the fiscal authorities in the periphery. To simplify, assume that all uncertainty regarding defaults is resolved once $t+1$ arrives. That is, from $t+1$ onwards, the government bonds always pay in full so their yield is the safe interest rate. In the default state of the world, the budget constraint is:

$$
\begin{array}{r}
c b_{t}^{p}+c^{e} b_{t}^{e}=p_{t+1}\left(\delta d_{t+1}+f_{t+1}\right)+ \\
\frac{b_{t+1}^{p}+b_{t+1}^{e}}{1+i_{t+1}}
\end{array}
$$

On the left-hand side are the payments on the bonds outstanding from last period. I 
allow for the payment to the central bank $c^{e}$ to be different from what is paid on the market $c$. In the first renegotiation of Greek debt, the ECB was senior relative to the private sector. On the right-hand side are the government revenues: (i) the fixed share $\delta$ of the central bank's dividends due to this country, (ii) its real fiscal primary surplus $f_{t+1}$, and (iii) the revenue from selling new bonds.

Iterating this equation forward, and not allowing the fiscal authority to run a Ponzi scheme with its private creditors, the intertemporal budget constraint of the periphery fiscal authority is:

$$
\begin{gathered}
\frac{c b_{t}^{p}}{p_{t+1}}=f_{t+1}+F_{t+1}+\delta\left(d_{t+1}+D_{t+1}\right) \\
-\frac{c^{e} b_{t}^{e}}{p_{t+1}}+\lim _{T \rightarrow \infty}\left(m_{t+1, T+1} \frac{b_{T}^{e}}{p_{T+1}}\right)
\end{gathered}
$$

where $F_{t+1}$ is the expected present value of future primary surpluses. This is the equilibrium equation that pins down $c$ as a function of real fiscal surpluses and other variables under the control of the central bank.

The second pillar describes how fiscal surpluses are determined. The crucial assumption is that $f_{t+1}+F_{t+1}=\Phi(c)$ where $\Phi($. is a weakly increasing function. Brunnermeier et al. (2011) argue that at the center of the European debt crisis has been a diabolic loop caused by banks holding too much of their home country's debt. A sovereign default makes domestic banks insolvent and causes a domestic financial crisis, which lowers tax revenues if it causes a recession, and raises public spending if it leads to a bailout of the financial sector. I will also assume that $\Phi($.$) is concave:$ the lower is the repayment on the sovereign bonds, the greater is the damage done to the financial system and the larger the resulting fall in the fiscal surplus.

To analyze the model, start with the case where the central bank is not an active player. This is the case when it keeps the price level on a target that I normalize to 1, when there is no seignorage revenue to distribute, and when the central banks does not hold any of the country's bonds. The equilibrium condition for $c$ in this case becomes:

$$
c b_{t+1}^{p}=\Phi(c) \text {. }
$$

Given the properties of the $\Phi($.$) function,$ this equation may have one or two solutions, depending on the sign of $\Phi(0)$.

If the diabolic loop is weak, so there is a positive fiscal surplus with full repudiation, $\Phi(0)>0$, then there is a unique equilibrium. Depending on whether the periphery is going through a fiscal crisis, so that fiscal revenues are not enough to fully repay the bonds, $\Phi(1)<b_{t}^{p}$, there may not be full repayment in this state of the world. If instead the government default has a large impact on the financial sector and on fiscal surpluses, so that $\Phi(0)<0$, there is also a second equilibrium. A severe debt crisis, with low $c$ and high sovereign yields, is possible because it creates the fiscal shortfall that will confirm the large debt repudiation.

Introduce now the central bank by going back to the general model in equation (8) to see whether it has the tools to raise the equilibrium debt repayment, $c$. The first action it could take to ameliorate the situation of the peripheral fiscal authority would be to raise fiscal surpluses, $f_{t+1}+F_{t+1}$, directly potentially eliminating the bad equilibrium. By stimulating economic activity, central banks are able to raise tax collection and lower benefits spending, but this would typically come with higher inflation.

Raising inflation would have the same effect by raising the seignorage that is distributed to the fiscal authorities. If $\delta\left(d_{t+1}+\right.$ $\left.D_{t+1}\right)+\Phi(0)>0$, it could eliminate the bad equilibrium. This mechanism is emphasized in Gourinchas and Jeanne (2012), and it involves a trade-off between eliminating default risk at the expense of inflation risk. As I argued in section I, there is an upper bound to how much seignorage the ECB can generate. Moreover, the strict Eurosystem rules fix the share of these dividends that can be sent to countries in crisis.

Higher prices would also erode the real value of debt. This can never eliminate the bad equilibrium, but it can raise repayment 
in the good equilibrium all the way to 1 . There is no limit to the size of this effect, although the increase in prices must be unexpected, for otherwise its effect would be neutralized by higher yields paid when selling the debt.

The central bank could also increase the share of the stock of sovereign debt it holds, raising $b_{t}^{e}$ and lowering $b_{t}^{p}$, to then write the debt off by lowering $c^{e}$. Alternatively, the central bank could take the other side of a Ponzi scheme run by the government, raising $b_{T}^{e}$. Either of these actions involves a redistribution from the other regions, and so it is subject to the limitations discussed in section III.

While all of these fundamental policies may have limited scope, if there is multiple equilibria, the central bank can perform another role. It can act as a coordinating device that steers the economy to the high-repayment equilibrium. With its deep pockets and hard-earned credibility, the central bank may well be the natural government agency to perform this role. Designing a policy that robustly achieves this goal requires carefully considering what information to reveal, how transparent to be, and how agents learn about the central bank's intentions. Realistically, the central bank may only be able to gain some time.

\section{The central bank's lever: Raising the inflation target.}

Most of the results in this paper have relied only on accounting relations and on ruling out arbitrage possibilities so that there exists a stochastic discount factor. I considered several different policy interventions by the central bank that could alleviate sovereign debt problems. For the most part, the answers were negative. The reality of the resource constraint that every central bank faces, and the statutes of the ECB when it comes to redistributions, either rule out or severely limit most fundamental policies that could generate resources. The most promising role for the central bank may be as selecting the best of multiple equilibria, even if only temporarily.

There is an alternative policy, discussed in all of the sections so far: to allow inflation to rise above target. Higher inflation would raise seignorage revenues, part of which would be distributed to the region in difficulties. Higher inflation would possibly raise nominal GDP growth which might raise fiscal surpluses and lower asset values if there is a default. Higher inflation would erode the value of the nominal debt, making full repayment more likely. Ultimately, this is the most effective lever at the disposal of a central bank to generate resources. It also makes clear that, once the mystique of the balance sheet is taken away, the choice facing a central bank during a crisis is a familiar one: to inflate or not.

\section{REFERENCES}

Brunnermeier, Markus, Luis Garicano, Philip R. Lane, Ricardo Reis Marco Pagano, Tano Santos, David Thesmar, Stijn Van Nieuwerburgh, and Dimitri Vayanos. 2011. "European Safe Bonds." euro-nomics.com.

Cagan, Phillip. 1956. "The Monetary Dynamics of Hyperinflations." In Studies in the Quantity Theory of Money. , ed. Milton Friedman, 25-117. The University of Chicago Press.

Gourinchas, Pierre-Olivier, and Olivier Jeanne. 2012. "Global Safe Assets." Bank for International Settlements Working Paper 399.

Hall, Robert E., and Ricardo Reis. 2012. "Controlling Inflation and Maintaining Central-Bank Solvency under New-Style Central Banking." Hoover Institution, Stanford University, and Columbia University.

Hilscher, Jens, Alon Raviv, and Ricardo Reis. 2013. "Measuring the Market Value of Central Bank Capital." Brandeis University and Columbia University.

Reis, Ricardo. 2009. "Interpreting the Unconventional U.S. Monetary Policy of 2007-09." Brookings Papers on Economic Activity, 40(Fall): 119-182. 